\title{
As conexões entre a literatura de cordel setecentista e a ascensão do romance em Portugal no século XIX
}

\author{
The relationship between cordel literature of eighteenth-century and \\ the rise of the novel in Portugal in the nineteenth century
}

\author{
MOIZEIS SOBREIRA DE SOUSA \\ Universidade de Campinas (UNICAMP/FAPESP)
}

\begin{abstract}
Resumo: É muito habitual pensar o romance português, sobretudo o volume de produção do século XIX, como um fenômeno ligado à importação do modelo romancístico francoinglês. Essa abordagem ignora o impacto que a tradição romancística portuguesa setecentista, muito habitualmente considerada como inexistente, teve sobre o romance do século XIX, nomeadamente a sua contribuição como elemento formativo. Com base nisso, este artigo tem por objetivo apresentar, em linhas gerais, a presença de fontes setecentistas lusitanas no romance português oitocentista, destacando dentre essas fontes a literatura de cordel e possíveis pontos de contato estabelecidos entre ela e a obra de romancistas portugueses do século XIX como Camilo Castelo Branco e Alexandre Herculano.
\end{abstract}

Palavras-chave: Romance; Literatura de cordel; Camilo Castelo Branco; Alexandre Herculano; António da Silva, o Mestre de Gramática

\begin{abstract}
It is very common to think about Portuguese novel as a phenomenon connected with the English and French novel. This approach ignores that the eighteenth-century Portuguese novel tradition had an impact on the nineteenth-century novel as a formative element. Based on this finding, this article aims to discuss the presence of Lusitanian eighteenth-century sources in the Portuguese novel of the nineteenth-century, highlighting among these sources the cordel literature and possible points of contact established between her and the novels of Portuguese authors of the nineteenth century as Camilo Castelo Branco and Alexandre Herculano.
\end{abstract}

Keywords: Novel; Cordel literature; Camilo Castelo Branco; Alexandre Herculano, António da Silva, o Mestre de Gramática

A problemática do romance português tem sido recorrentemente ignorada. Assumido peremptoriamente como um modelo importado, os seus desdobramentos são recebidos como extensão do tronco romancístico franco-inglês. Essa abordagem impossibilita considerar as questões específicas e os caracteres que o romance adquire no espaço cultural lusitano.

Quando o romance franco-inglê cruza os Pirineus, não encontra Portugal em estado lacunar. O romance português já existe e segue o seu próprio caminho. O cenário lusitano não deixa pensar na ocorrência de romances antes de haver romancistas, situação que, segundo Roberto Schwarz (2000), descreveria a realidade brasileira. Antes da chegada dos romances franceses e ingleses, Portugal concentra um acervo numeroso de escritores, obras e modelos narrativos enraizados na comunidade lusitana e peninsular, o que impossibilita subscrever a noção de romance enquanto produto de uma importação cultural. Já no século XVIII, esse gênero dispõe de cidadania portuguesa, dando sequência à orquestração de uma tradição ficcional calcada em contiguidades nacionais, em processo desde a Idade Média.

Tendo em vista que as pesquisas dedicadas ao romance português têm sido pautadas pela busca de correspondência entre os desdobramentos dessa forma em Portugal e os parâmetros fixados na França e Inglaterra, parece necessário tomar como eixo a demonstração de fontes lusitanas que atuam nos processos de desenvolvimento do romance português. Assim, um caminho possível seria demonstrar os pontos de contato que os romancistas portugueses do século XIX estabelecem com os compatriotas setecentistas, sublinhando o quanto esse contato estrutura as formas que o romance adquire em Portugal nos Oitocentos. 
No atlas de formas narrativas setecentistas, merece destaque a literatura de cordel, cujos folhetos abrigavam uma extensa variedade de autores, gêneros e motivos textuais. Pelas folhas volantes, passavam peças de teatro, autos sobre a vida de santos e pessoas ilustres, romances em prosa ou verso, notícias, relatos (relações) de acontecimentos sociais e narrativas de viagens, conteúdo moralizante e crítica social, "assim como [...] textos de gosto picaresco e maravilhoso ou fantástico, para além daqueles que [pretendiam], na gênese da própria imprensa, fazer o acompanhamento mais ou menos fiel dos acontecimentos que se iam produzindo por Portugal e pelo mundo" (RAMOS, 2008, p. 91) ${ }^{1}$.

Do ponto de vista econômico, os folhetos de cordel apresentavam um conjunto de facilidades. O baixo custo dos exemplares proporcionava a circulação dos textos a uma ampla audiência, formada, inclusive, por pessoas oriundas dos estratos sociais que não tinham acesso ao circuito cultural canônico. Some-se a isso a proximidade dessa literatura com a oralidade, o que se convertia na vantagem de incluir uma parcela significativa de leitoresouvintes (analfabetos e semianalfabetos) ${ }^{2}$. Nesse contexto

\footnotetext{
Entre as produções mais procuradas, Ana Margarida Ramos (2008, p. 25) destaca "a poesia dos cancioneiros, os relatos de feitos extraordinários ou os segmentos mais importantes de novelas ou comédias". A partir do folheto Escudo apologético contraposto aos golpes de descuido crítico, publicado em 1732, é possível reconstituir com mais precisão os livros mais populares no século XVIII. Nesse folheto, consta a lista das principais obras lidas e comercializadas à época. São elas "Auto e colóquio do Nascimento, Auto de Santo Aleixo, Auto de Santo Antônio, Auto de Santa Bárbara, Auto de Santa Catarina, Auto de Santa Maria Egipcíaco, Auto ou a Vida de São João de Deus, Auto do Dia do Juízo, Auto da Barca, Auto do Fidalgo Aprendiz, Auto das Padeiras, Auto do Caseiro d'Alvalade, Auto da Segunda Barca, Conselho para bem casar, Pranto de Maria Parda, Infante D. Pedro, Auto de D. Duardos, Tratado dos Passos, Lazarillo de Tormes, Avisos contras os Enganos, Prática das Três Comadres, Tratado da Lição da Espada Preta, Trovas da Menina Formosa, Magalona, Marques de Mântua, Valdevinos, Imperatriz Porcina, Malicia das Mulheres, Terremoto de Roma, Ousadia do Menino Morto, Novo Auto da Barca, Auto da Fortaleza" (BRAGA, 1986, p. 334). Na segunda metade do Século, Teófilo Braga afirma, com base num catálogo dos folhetos vendidos na Rua Augusta em 1783, os textos mais difundidos foram: "História nova de João de Calais, dos grandes trabalhos que padeceu e a fortuna que teve depois; História da Imperatriz Porcina, mulher do Imperador de Roma, e suas virtudes e trabalhos; História da princesa Magalona, e seus amores e trabalhos, História de Roberto do Diabo. Que depois mereceu por sua penitência ser chamado Roberto de Deus; História do Marquês de Mântua, que conta a história que ela faz dar ao filho do imperador Carlos Magno; História Verdadeira acontecida no Algarve a D. Pedro e D. Francisca; História de Reinaldos de Montalvão, um dos Doze Pares de França; Livro do Infante D. Pedro, que correu as sete partidas do mundo; Vida e formosas ações do célebre Cosme Manhoso, três partes; Autos de Santo Aleixo, Santa Bárbara, Santa Catarina, do Dia do Juízo, da Paixão, de Jesus Cristo, de Santa Bárbara, e todas as qualidade de comédias e entremezes; Astúcias subtilíssimas de Bertold. As obras de outro escritor popular José Daniel Rodrigues da Costa, tais como $O$ piolho viajante, $O$ Almocreve das Petas e Barca da Carreira dos tolos foram bastante lidas, mas não entraram na corrente da vulgarização" (BRAGA, 1986, p. 339).

2 Ana Margarida Ramos ressalta que o conceito de analfabetismo nesse contexto pode derivar em falácia, já a quantidade de pessoas que sabem ler não corresponde efetivamente às que tem acesso à leitura. Assim, "o analfabetismo não surgia como obstáculo à fruição [...] do texto, que atingia o seu objetivo de chegar junto do seu leitor/ouvinte" (RAMOS, 2008, p. 31).
}

específico, a prática da leitura vozeada promovia a criação de redes de leitura em que as obras eram compartilhadas coletivamente, fosse nos serões familiares ou nos círculos de vizinhos. Essa ampliação do público trouxe como consequências o aumento do número de autores, crescimento da produção de livros, criação de hábitos e costumes de leituras, desenvolvimento do mercado de livro e favorece profissionalização da escrita. A relação entre público e literatura de cordel se tornou tão estreita a ponto de "podermos ver reproduzida a consciência coletiva de um grupo, a maneira de pensar de uma sociedade e o comportamento humano numa determinada época" (RAMOS, 2008, p. 42).

O sistema de escrita e circulação dos impressos arregimentado pelo cordel possui muitos pontos de contatos com técnicas narrativas e modos de difusão da escrita no século XIX. Exemplo claro disso é o folhetim, cujo dinamismo e êxito editorial estão fundados, em grande parte, na herança deixada pelas folhas volantes ${ }^{3}$. Ao contrário do que propõe Gonçalves Rodrigues (1951), a presença arraigada da literatura de cordel na cultural portuguesa setecentista não serve como argumento para justificar a pretensa ausência do romance. Na verdade, o cordel representa um espaço privilegiado para o desenvolvimento do romance que se consolida nos Oitocentos. Está-te diante de um genuíno laboratório, onde o romance se manifesta, como lhe é próprio, em processo, desenvolvendo formas, gostos e circuitos narrativos. A tradição narrativa portuguesa, particularmente a tradicional e popular, encontra, ao longo do século XVIII, garantia de perpetuação no cordel. Enquanto, os gêneros elevados e canônicos resistiam à plasticidade do romance, as folhas volantes o albergavam e com ele mantinha estreita comunhão.

Não parece mera casualidade que Camilo Castelo Branco, em cuja pena o romance se consolidou como gênero predominante em Portugal, tenha ingressado no universo romancístico através de um folheto de cordel: a narrativa Maria,não me mates, que sou tua mãe! A época de publicação desse texto - 1848 - coincide com o período em que Camilo faz suas primeiras experiências nos domínios da escrita romancística, o que sugere que a apropriação dessa forma tenha passado pelo manuseio da orientação discursiva fixada no cordel. Esse aspecto se reveste ainda mais de significado se for levado em conta que muitos dos traços que notabilizam o autor de Amor de Perdição como romancista ao longo de toda a sua carreira estão postos na obra em questão, tais como exploração estratégica dos interesses do público leitor e pintura de

\footnotetext{
Essa hipótese também é partilhada por Ana Margarida Ramos (2008). Em sua opinião, a literatura de cordel partilha, com o folhetim, textos, motivos, estratégias, público a quem se dirigia e o baixo custo exigido pelas edições.
} 
cenas relativas à vida das classes populares a partir de um ângulo vulgar e quotidiano.

A origem de Maria, não me mates, que sou tua mãe está baseada numa notícia que foi divulgada pelo jornal Revolução de Setembro e que teve grande repercussão na época. Partindo desse fato, Camilo elabora um esquema narrativo-editorial claramente empenhado em manipular os gostos do público e obter boa audiência para seu texto. Já na capa, é possível perceber o apelo publicitário que direciona a obra. Tal como nos folhetos tradicionais, o título é bastante extenso, de modo a oferecer um resumo da obra, destacando suas qualidades e interpelando o público. Na íntegra, o título sai assim na primeira edição:

\section{MARIA! NÃO ME MATES, QUE SOU TUA MÃE! MEDITAÇÃO SOBRE O ESPANTOSO CRIME ACONTECIDO EM LISBOA; UMA FILHA QUE MATA E DESPEDAÇA SUA MÃE/Mandada imprimir por um mendigo, que foi lançado fora do seu convento, e anda pedindo esmolas pelas por- tas. OEFERECIDA Aos pais de famílias, e àqueles que acreditam em Deus. (CASTELO BRANCO, 1991, p. 4$)^{4}$.}

Essa estratégia editorial, baseada no apelo ao senso moral corrente, na proximidade entre os fatos narrados e o mundo referencial que integra a vida corrente, e na tentativa de mobilizar a sensibilidade do público, logrou um êxito expressivo. De acordo com Paulo Motta Oliveira (2011), entre 1848 e 1852, Maria, não me mates, que sou tua mãe foi editada quatro vezes, o que, no contexto do século XIX, é equivalente à tiragem de um best-seller, posição que essa narrativa, de fato, ocupa na primeira metade dos Oitocentos. Como tal, é razoável supor que a técnica narrativa empregada nessa obra acompanha "coordenadas mentais, os gostos e as preferências literárias e estética do público" (SOBREIRA, 2001, p.3) da época, donde se conclui que a ficção transportada nas folhas de cordel continuava no horizonte de preferência dos leitores de então.

Em A Brasileira de Prazins, Camilo coloca no bolso de um homem rústico e do povo, o personagem Simão, um exemplar do Auto de Santa Bárbara, texto listado entre os mais populares da literatura de cordel setecentista. Apesar de figurar numa obra ficcional, essa ocorrência reforça a presença do cordel como uma constante no gosto do

\footnotetext{
4 Na Terceira edição, sem data, consta o seguinte título: "MATRICÍDIO SEM EXEMPLO. UMA FILHA que matou e esquartejou sua própria MÃE, MATILDE DO ROSARIO DA LUZ, EM Lisboa - na travessa das freiras, $\mathrm{n}$ - 17. Às almas sensíveis - aos pais de família - e aos bons cristãos oferece-se em meditação, a descrição do atentado praticado pela perversa matricida Maria José = seguido do interrogatório da acusada, e de sentença do tribunal do $1^{\mathrm{O}}$ distrito, que a condenou a morrer numa forca, no Campo de Santa Clara, em Lisboa" (CASTELO BRANCO, 1991, p. 30).
}

público da década de 1840, período que o romance em causa recobre. Ao contrário do que ocorreu na França, onde a ascensão do romance em folhetim contribuiu para o declínio da literatura de cordel, "esses suportes coexistem em Portugal" (cf. SOBREIRA, 2001, p.3). Ora, tal persistência, no momento em que o mercado editorial é forte o bastante para prescindir definitivamente do circuito volante, fortalece a ideia segundo a qual a tradição literária ligada ao cordel é um dado que aponta para as particularidades do sistema cultural peninsular e não sintoma do atraso português.

Não obstante a relevância desse patrimônio monumental, a crítica e história literária preferem desqualificá-lo, de modo a reduzi-lo à condição de dado etnográfico, ou sonegando o papel que ele desempenha como celeiro de narrativas e plataforma da escrita romancística lusitana. Ao tratar dos textos que Camilo produz na fase inicial de sua carreira, dentre os quais se encontra Maria, não me mates que sou tua mãe!, António José Saraiva e Óscar Lopes os enquadram na categoria da tendência melodramática, marcada por enredos de terror macabro, com enjeitados, raptos, prisões e crimes, formato que Camilo teria incorporado a partir do arremedo do romance negro de aventuras, oriundo do pré-romantismo inglês e do melodrama ao gosto de Pixérécourt, Soulié, Nodier, Féval, Sue e o Victor Hugo. Eles ainda acrescentam que o folhetim, conforme modelo consagrado na França, teria servido de baliza para o romance camiliano. Até certo ponto, o contato com essas as influências externas age como elemento formador em Camilo. Seria descabido não levar isso em conta. Contudo, essa perspectiva encobre o parentesco da escrita romancística camiliana e portuguesa com o cordel, que, como essas influências externas também se vale de muitos expedientes melodramáticos.

No conjunto da literatura de cordel, se destacam as relações (relatos), um dos subgêneros mais fecundos desse tipo de literatura nos Setecentos. As relações podiam ser designadas como notícia, cópia de uma carta ou história. Geralmente, essas designações eram acompanhadas por um ou mais adjetivos. Assim, surgiam casos "como relação verdadeira, notícia rara ou curiosa, notícia verdadeira, nova e curiosa relação, curiosa notícia e certa relação, nova e verdadeira relação, relação e breve notícia, nova relação e suplemento à notícia, nova relação, notícia verdadeira $\mathrm{e}$ curiosa" (RAMOS, 2008, p. 140), sintagmas que exerciam a função de situar o gênero textual e seduzir o leitor, apelando para a sua curiosidade, veracidade e proximidade.

É seguro o contato do autor de Amor de Perdição com as relações. Em um dos catálogos de sua biblioteca - Catalogo da preciosa biblioteca do eminente escriptor Camilo Castello Branco - as relações aparecem variada e abundantemente. Aos diversos títulos, se somam 
best-sellers setecentistas, como Relação da prisão e morte dos quatro veneraveis padres da Companhia de Jesus... mortos em odio da fé na corte de Tinkim aos 12 de Janeiro de 1737 e Nova e fiel relação do terremoto... no 1 de Novembro de 1755.

Embora filiados ao gênero jornalístico, esses textos possuem um acentuado valor literário. Valendo-se de uma base formal elástica, as relações incidem sobre múltiplos aspectos da vida portuguesa setecentista, abordando assuntos políticos, temas ligados à corte, ao imaginário, doxa e quotidiano do povo, bem como à sociedade de modo geral.

Como exemplo dessas constantes, podemos mencionar a Relaçam curiosa da varanda em que se celebrou a Aclamaçam i Exaltaçam ao Trono de D. Joseph I, Nosso Senhor (1750), Relação da vitória alcançada contra os argelinos dos mares da Barbaria (1752), Relação do tumulto popular que succedeo em 18 de dezembro do ano passado de 1754 na cidade do Grão Cairo (1755), Verdadeira notícia e curiosa relação do grande e lastimoso caso que succedeo na Ilha de Santa Elena por oscasião de hum horrivel Terremoto (1755), Nova, e fiel relação do terremoto que experimentou Lisboa, e todo Portugal no 1. De Novembro de 1755. com algumas observaçoens curiosas, e a explicação das suas causas (1756), Nova relação das entradas das festas de touros que se hão de fazer na cidade de Lisboa em que se hão de saracotear varias dançadeiras (1752), Nova relaçam de huma disputa que teve huma couveira com huma cozinheira (1752), Cópia de huma carta escrita por hum amigo a outro com a notícia do prodígio sucedido na vila de Montemor-o-Novo, no nascimento de uma menina com duas cabeças unidas (1754), Relação da prizão e morte dos quatro veneraveis padres da Companhia de Jesus, Bartholomeo Alvarez, Manuel de Abreu, Vicente da Cunha (Portugueses) e João Gaspar Cratz (Alemão) mortos em ódio de Fê na Corte de Tunkin aos 12 de Janeiro de 1737 (1738), História verdadeira acontecida no Reino do Algarve, na qual se referem os sucessos de huma virtuosa dama, no tempo que foi escrava do imperador dos turcos (1785), Relação curiosa da fugida que fez huma velha para o desterro, com temor de ser serrada na presente quaresma, pelo grande, e justo medos dos rapazes, e mais plebe, e o encontro que teve com hum pastor, as fallas que tiverão, e como este aconduziu a huma cova deserta a donde ficou segura (1785) e Novella curioza que contém a rapariga de duas mãis ou os amores encubertos e a fingida prenhez (1789).

A partir do exame dos títulos desses textos, que são bastante sugestivos, chegando a resumir o que o leitor encontrará nas páginas seguintes, é possível apurar muitos dos assuntos que povoam a vida social portuguesa do século XVIII: a coroação de D. José I, as corridas de touro realizadas no Terreiro do Paço, o Terremoto de 1755 , as disputas entre vizinhos, os jesuítas, os mitos e lendas populares, a quaresma e os conflitos da moral católica frente a outras confissões religiosas e preceitos filosóficos heterodoxos. Essa variedade temática encontra correspondência no modo como a realidade é captada nas relações. Múltiplos níveis do real são abarcados, de maneira que eventos extraídos do âmbito factual surgem ao lado de lances maravilhoso-fantásticos. Assim, questões do campo histórico e jornalístico, como batalhas, cercos, fenômenos naturais, crimes e julgamentos, compartilham as folhas das relações com narrativas sobre monstros, milagres, prodígios e viagens (navegações, peregrinações e aventuras), nas quais a ordem natural se altera e absorve "seres estranhos e figuras compósitas, afastadas totalmente das representações [do] universo empírico" (RAMOS, 2008, p. 101).

A despeito da incidência ou não do insólito, as relações insistem na veracidade da matéria veiculada, apresentando como verdadeiros até mesmo os fenômenos que transgrediam os limites da probabilidade, geralmente explicados "como forma de comunicação da vontade divina, infinitamente superior à humana" (RAMOS, 2008, p.99). Em razão disso, as noções de realidade e ficção não colidem entre si, permitindo a elaboração de um sofisticado pacto ficcional, precursor em muitos aspectos do efeito de realidade em que se assenta o romance mais típico do século XIX.

A construção desse pacto resulta do manejo estratégico de elementos que visam caucionar a impressão de verdade. Assim, são disponibilizados dados do mundo referencial que o leitor é capaz de reconhecer como factíveis. A par da opção pela forma jornalística e das estruturas formais da carta e crônica, o aproveitamento de datas, quantidades, medidas, localização espacial precisa e fatos historicamente comprovados estão entre os recursos mais comuns para se atingir a simulação de realidade nas relações. A esse propósito, veja-se, por exemplo, a Relaçam de hum caso notavel, espantoso, e horrivel, novamente sucedido em a Provincia de AlemTejo em 11 de Julho do anno presente de 1756, nas praças de Elvas e Olivença. Esse folheto dá conta de uma repentina nuvem de gafanhotos que teria assolado as proximidades de Elvas, sendo que o número de insetos privava a todos da vista do sol e excedia a quantidade de átomos desse corpo celeste. Além disso, quando pousava sobre alguma plantação, formava um cardume de dois palmos de altura. A solução encontrada para resolver o problema foi realizar uma procissão em louvor a São João de Deus, o qual prontamente atendeu o clamor do povo, afogando os gafanhotos no rio Guadiana. Todavia, após pouco tempo de sossego, os moradores são assolados por 
outra tormenta, uma tempestade que fez cair pedras de aproximadamente três quilos.

Todo o relato é acompanhado pelo detalhamento minucioso dos referenciais que embasam a ação. Do ponto de vista espacial, ela se situa em Elvas e no rio Guadiana, locais que correspondem a coordenadas topográficas factuais. No que tange ao tempo, o nível de especificação é ainda maior. Inicialmente, os índices cronológicos remetem à época do Terremoto de 1755 . Em seguida, o oferecimento dos detalhes avança gradativamente e chega ao ano de 1756, sucedido pelas informações acerca do mês (julho), dias (11-12) e horas (11h00 do dia 11 até perto das 10 horas do dia seguinte) $)^{5}$. Essa tessitura pormenorizada é vertida em favor da construção do efeito de verossimilhança, que precisa ser suficientemente convincente para contornar os eventos que destoam do tangível, tais como a dimensão das pedras que caem durante a tempestade, os milagres que diluem repentinamente os problemas e o volume dos gafanhotos, os quais, cumpre sublinhar, também são alvos de uma ação discriminadora por parte do narrador, ainda que as medidas empregadas para atingir esse fim ultrapassem os limites da probabilidade. Nesse sentido, Ana Margarida Ramos nota que, quanto mais o fato relatado foge à realidade e às leis naturais do mundo empírico, maior é o esforço do seu autor em reiterar a questão da verdade, recorrendo às estratégias mais ou menos sutis para convencer o leitor. Nesses estratagemas, além do rigor e precisão jornalística na apresentação das circunstâncias espaço-temporais, incluem-se "a minúcia na descrição do fenômeno estranho, condicionando a leitura pela quase aproximação científica aos fatos narrados" (RAMOS, 2008, p. 148).

Grosso modo, esses estratagemas não diferem muitos dos recursos alocados pelos romancistas do século XIX para corroborar a ilusão realista. Em Maria, não me mates, que sou tua mãe!, Camilo abre a história com o detalhamento das coordenadas espaciais. Já nas primeiras linhas, o leitor é informado de que o relato se passa "em Lisboa, na Travessa das Freiras, no 17 ", (CASTELO BRANCO, 1991, p.7). Na sequência, esses dados se somam a outros que encaminham a leitura na mesma direção, reforçando, no narrador, a condição de informante daquilo que realmente se passa no mundo. $\mathrm{Na}$ terceira edição do folheto, a representação desse papel chega, por exemplo, ao ponto de transcrever aquilo que teriam sido os autos do julgamento do crime que a protagonista Maria José cometera. Para os leitores coevos, previamente esclarecidos acerca desses sucessos, assinar esse tipo de contrato ficcional não exigia esforço.

\footnotetext{
5 Os dados sobre o ano, mês, dia e hora se referem especificamente à tempestade de pedras.
}

A par da contextualização espaço-temporal e do registro linguístico quotidiano, a construção do pacto ficcional das relações ainda se valia do reaproveitamento de histórias que compunham o repertório do imaginário popular, especialmente os textos ligados à Idade Média (romances de cavalaria), que persistiam no gosto do público e na influência que exerciam sobre os escritores setecentistas.

No tema da retomada da literatura medieval pelas relações setecentistas, cabe registrar a produção de António da Silva, o Mestre de Gramática. Sobre esse autor, são escassas as informações. Nada se sabe acerca de sua biografia. As únicas referências de que se tem conhecimento estão no Diccionario bibliographico portuguez (Vol VIII), no qual Inocêncio Francisco da Silva faz menção à autoria do folheto Lançarote do Lago, e no artigo Two Eighteenth-Century Chapbook Romances of Chivalry by António da Silva, Mestre de Gramática: Lançarote do Lago and Dário Lobondo Alexandrino, em que Harvey Sharrer faz um levantamento das principais obras dele. De acordo com essa recensão, há quatro folhetos de Silva que se destacam: História verdadeira da vida, e valerosas acçoens do esforçado, magnânimo, $e$ invencivel Bernardo del Carpio Sobrinho del Rey D. Affonso o Casto, publicado em 1745; Labyrintho Affectuoso, fabricado de hum enredo trágico pelo odio. Novella intitulada verdadeiramente Caudalosa Torrente de furores, Fonte de manifestos, Mar tempestuoso de iras, em que se viraõ os mais finos amantes, a discreta, e sabia Narcisa, e o valente animoso Principe Girasol, hereditario, e unico filho de Merlim Rey Mouro, publicado em 1750; Historia notavel, em que se trata da vida e valerosas obras do animoso Cavalleiro Andante Lançarote do Lago. Extrahida das Chronicas Francezas, vinda à estampa em 1746; e Emboscadas tragicas, e relaçam lastimosa, em que se refere a vida, acçoens heroicas, e cruel morte, que os mouros sem nenhuma piedade deraõ no Reyno de Galiza a Dario Lobondo Alexandrino, publicada em 1750.

Em História verdadeira da vida, e valerosas acçoens do esforçado, magnânimo, e invencivel Bernardo del Carpio Sobrinho del Rey D. Affonso o Casto, Silva retroage ao século XIII, de onde recupera as façanhas de Bernardo del Carpio. A ação se passa, como em outras versões, na Espanha visigótica, mais precisamente durante o reinado de Afonso II das Astúrias, entre 791 e 842. O valor cavalheiresco de Bernardo é demonstrado particularmente contra os mouros, inimigo dos cristãos peninsulares naquela altura. A sua consagração é obtida com a tomada de Carpio, cidade que ele livra do controle mulçumano. Nessa ocasião, Bernardo mata mais de cem homens instantaneamente, fazendo-se "Senhor de Carpio em menos de huma hora" (cf. SILVA, 1745, p. 17). 
O Mestre de Gramática constrói o Invencivel Bernardo del Carpio de uma maneira que faz lembrar em muitos aspectos, Eurico, de Eurico, o presbitero, de Alexandre Herculano. As similitudes entre esses protagonistas são flagrantes. Em primeiro lugar, a ação do romance de Herculano se passa num espaço e tempo (Espanha visigótica) igual ou muito próximo ao retratado na História verdadeira da vida, e valerosas acçoens do esforçado, magnânimo, e invencivel Bernardo del Carpio. Em seguida, o inimigo de ambos é, até certo ponto, representado pelo mesmo arquétipo, isto é, o mouro. Por fim, os valores e feitos que compõe a trajetória de Eurico são bastante similares aos que Bernardo carrega. Tanto um quanto o outro, é capaz de derrotar, sozinho, uma quantidade extraordinária de inimigos num curto intervalo. Essa constatação fortalece a hipótese segundo a qual o romance português se distingue pela incorporação da matriz cavalheiresca peninsular e evidencia os vínculos que a relação e demais narrativas do século XVIII que circulavam no cordel tem com a escrita romancística dos Oitocentos.

Como o setecentista António Silva, Alexandre Herculano buscou elementos para construir suas narrativas na tradição medieval. No conjunto de sua produção romancística, a maior parte dos textos é ambientada na Idade Média. Em Lendas e Narrativas, apenas dois textos tratam diretamente de questões relativas ao século XIX. Se tivermos em conta, como defende Herculano em 1858, que suas obras exercem um papel fundante na implantação do romance (histórico) em Portugal, não podemos perder de vista que os "monumentos desses esforços" também se articulam à recuperação da tradição medieval que vinha sendo feita também pelas narrativas que circulavam nos cordéis do século XVIII. Nesse sentido, as análises que ligam o romance histórico de Alexandre Herculano somente à transferência do modelo scottiano se mostram limitadas para entender a obliquidade dos movimentos da escrita romancística. Em alguma medida, as Lendas e narrativas, "que, na sua maioria, são quase a transcrição de capítulos das crónicas medievais" (MARINHO, 1999, p. 54), bem como os demais escritos romancísticos de Herculano que são calcados na reconstituição histórica do passado, donde resulta uma estrutura híbrida, simultaneamente fictícia e referencial, dialogam expli- citam com motivos e procedimentos que integram o diapasão narrativo sintetizado pelas relações.

Não cabe equiparar o valor dessas narrativas (relações) à envergadura estrutural de um romance oitocentista, tal como constituído nas penas de Herculano ou Camilo, por exemplo. Entretanto, elas permitem detectar um espaço em que a prosa de ficção esteve abrigada no século XVIII. Espaço esse que funcionou como laboratório para o texto romancístico ensaiar mecanismos, temas e o manejo da técnica ficcional que o notabilizou no século XIX, além de permiti-lo organizar o suporte editorial que lhe propiciou condições para se tornar o gênero literário dominante. Se levadas em conta, destacando-se os pontos de convergência entre essas estruturas narrativas e o romance oitocentista português, será possível compreender com mais acuidade este último, de maneira enquadrá-lo não mais como um mero produto da importação do modelo romancístico franco-inglês.

\section{Referências}

CASTELO BRANCO, Camilo. Maria, não me mates, que sou tua mãe! São Paulo: Edições Loyola; Editora Giordano, 1991.

MARINHO, Maria de Fátima. O romance histórico em Portugal. Porto: Campo das Letras, 1999.

OLIVEIRA, Paulo Motta. Cartografia de muitos embates a ascensão do romance em Portugal. Floema, ano VII, n. 9, p. 249-282, jan./jun. 2011.

RAMOS, Ana Margarida. Os monstros na literatura de cordel portuguesa do século XVIII. Lisboa: Edições Colibri, 2008.

SCHWARZ, Roberto. Ao vencedor as batatas. 5. ed. São Paulo: Duas Cidades; Ed. 34, 2000.

SILVA, António. História verdadeira da vida, e valerosas acçoens do esforçado, magnânimo, e invencivel Bernardo del Carpio Sobrinho del Rey D. Affonso o Casto. Lisboa: Officina de Pedro Ferreira, 1745.

SOBREIRA, Luis. Uma imagem do campo literário português no período romântico através dos best-sellers produzidos entre 1840 e 1860. Évora: Atas do IV Congresso Internacional da Associação Portuguesa de Literatura Comparada, 2001. p. 1-15.

Recebido: 16 de março de 2016 Aprovado: 07 de setembro de 2017 Contato:moizeis.ssousa@gmail.com (Moizeis Sobreira de Sousa) 